\title{
Multi-Band Heterogeneous Wireless Network Architecture for Industrial Automation: A Techno- Economic Analysis
}

Koushik Araseethota Manjunatha ( $\sim$ koushik.manjunatha@inl.gov )

Idaho National laboratory https://orcid.org/0000-0002-6277-770X

Vivek Agarwal

Idaho National Laboratory

\section{Research Article}

Keywords: Distributed Antenna System, Techno-Economic Analysis, Wireless Network, Quality of Service

Posted Date: March 24th, 2021

DOI: https://doi.org/10.21203/rs.3.rs-163125/v1

License: (c) (1) This work is licensed under a Creative Commons Attribution 4.0 International License.

Read Full License

Version of Record: A version of this preprint was published at Wireless Personal Communications on January 24th, 2022. See the published version at https://doi.org/10.1007/s11277-021-09303-4. 


\section{Abstract}

To attain automation across different applications, industries are beginning to leverage advancements in wireless communication technologies. A "one-size-fits-all" solution cannot be applied since wireless technologies are selected according to application needs, quality of service requirements, and economic restrictions. To balance the trade-off between technical and economic requirements, a multi-band heterogeneous wireless network architecture is presented and discussed in this paper. Wireless local area network (WLAN) and distributed antenna system (DAS) with Long Term Evolution (LTE) are considered as the backbone for the multi-band heterogeneous network into which other wireless technologies can be integrated. The technical and economic feasibility of the network are evaluated through a technoeconomic analysis (TEA). The economic feasibility of the proposed network is measured in terms of net present value while the technical feasibility is measured in terms of network throughput and latency. Finally, network performance for DAS with LTE and WLAN are verified using an NS3 simulator for machine-to-machine, real-time video, and high-definition video data transmissions. The TEA analysis showed that the number of DAS units required to achieve technical feasibility is less than WLAN units, but the overall cost of DAS units are higher compared to WLAN units, even without taking into consideration industrial, scientific, and medical band technologies.

\section{Full Text}

Due to technical limitations, full-text HTML conversion of this manuscript could not be completed. However, the latest manuscript can be downloaded and accessed as a PDF.

\section{Figures}

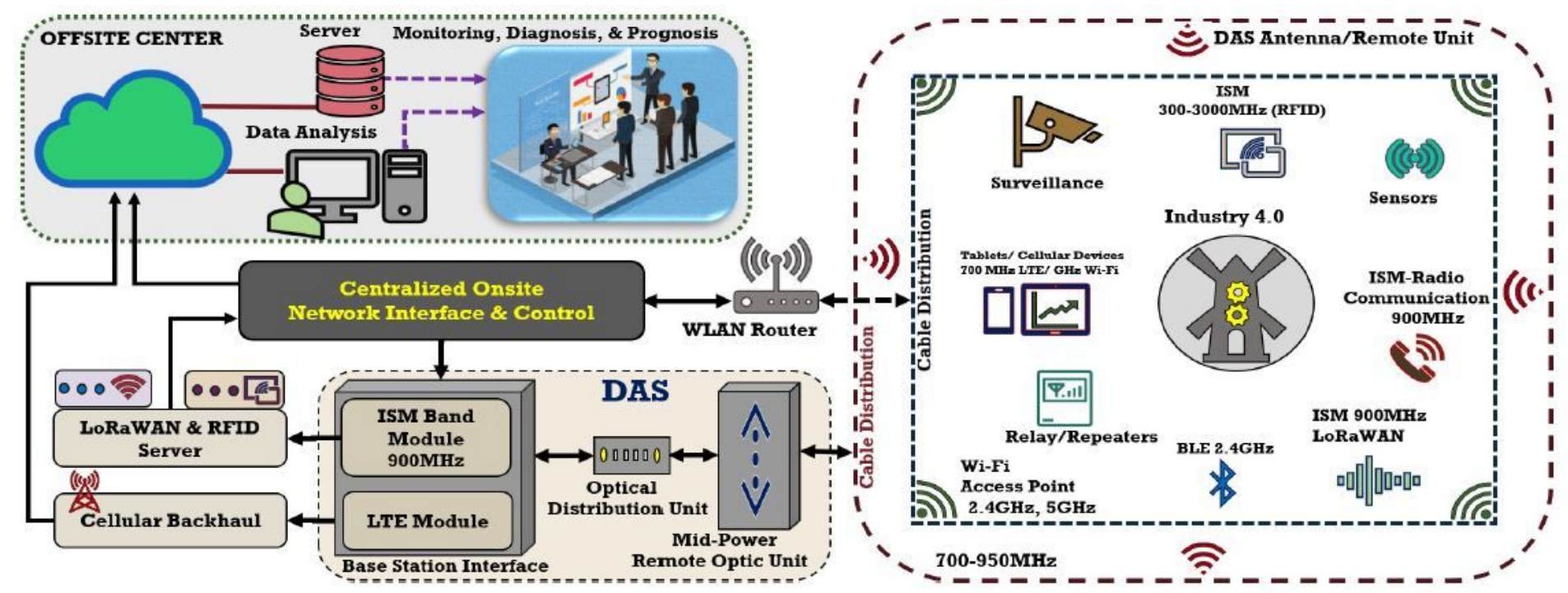

Figure 1

Proposed wireless network architecture for industrial automation. 


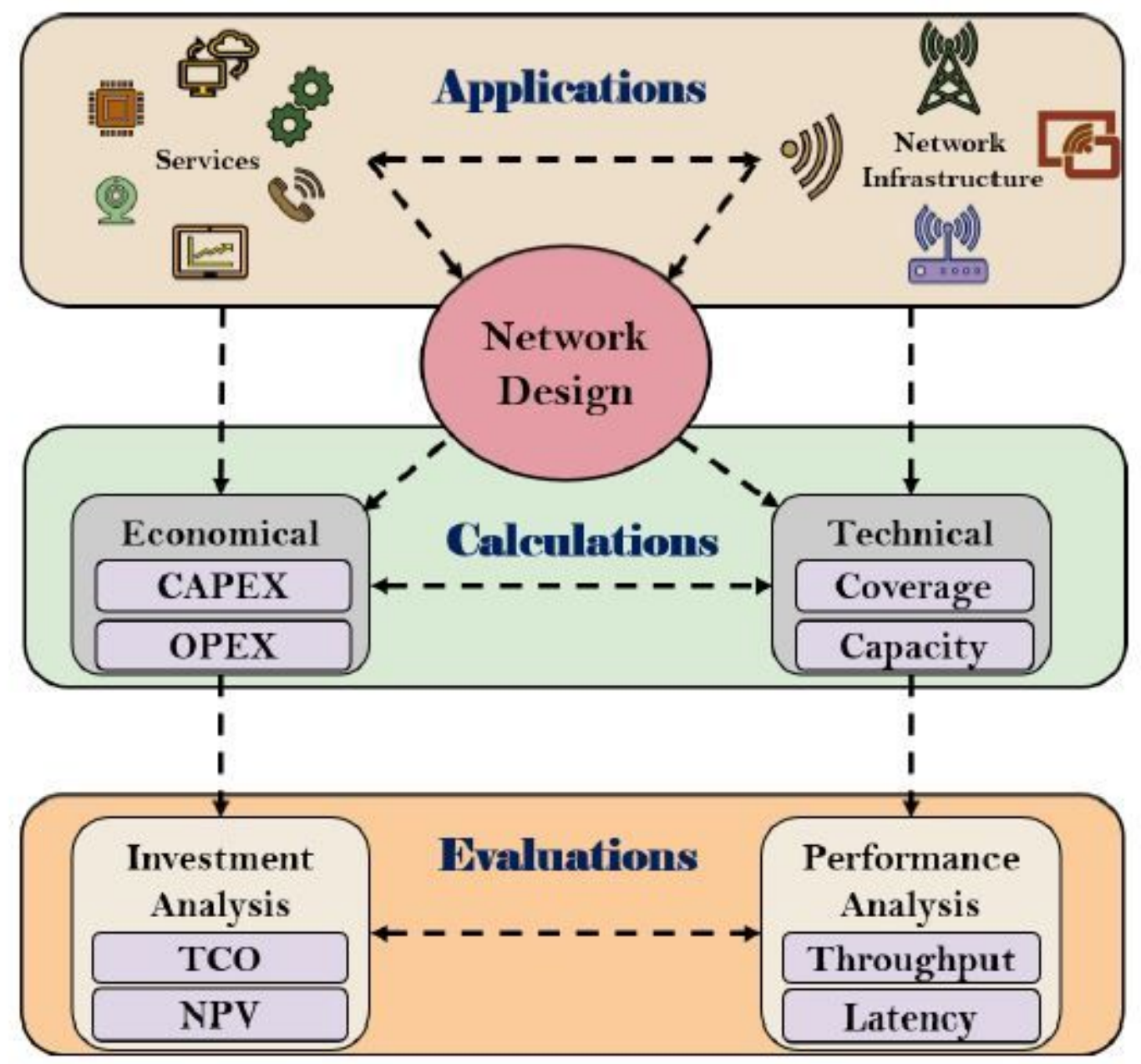

Figure 2

Flow diagram of a TEA model.

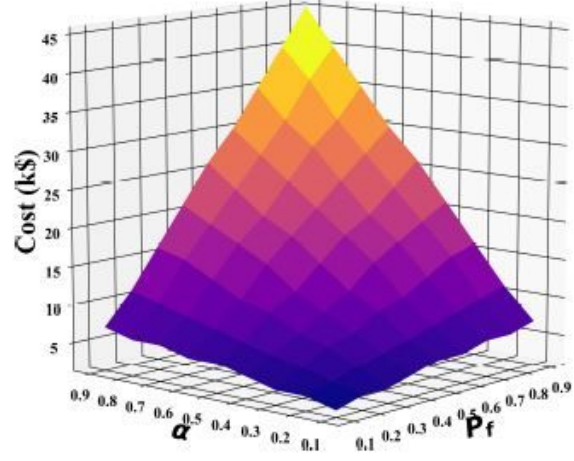

(a) DAS

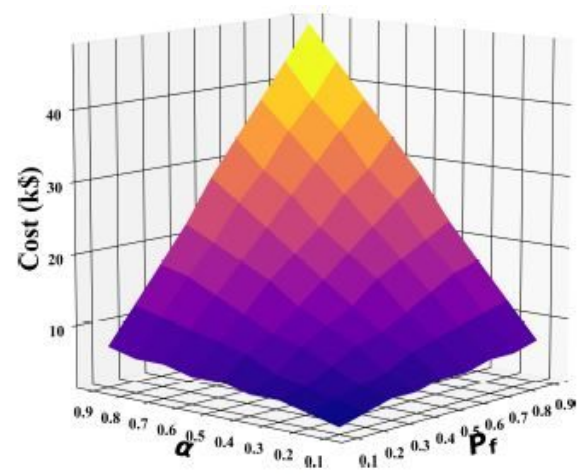

(b) DAS + ISM

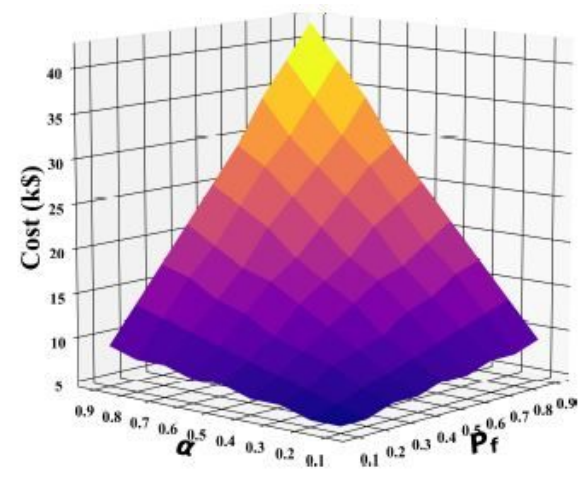

(c) WLAN

Figure 3

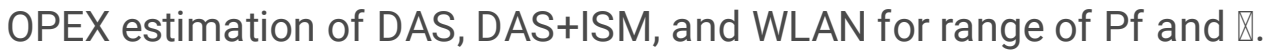




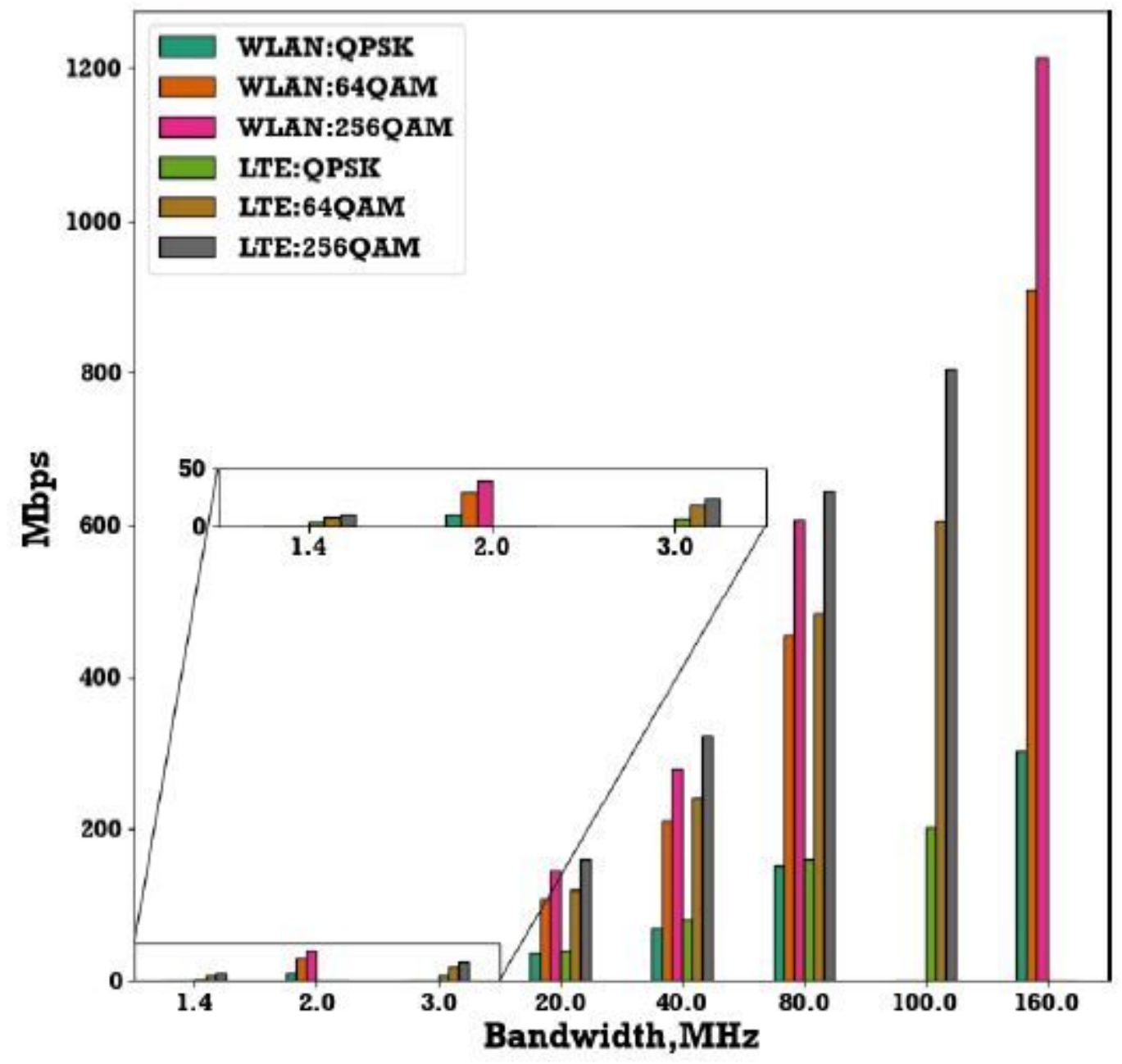

Figure 4

Throughput per DA in LTE-DAS and AP in WiFi-6 for different bandwidths. 


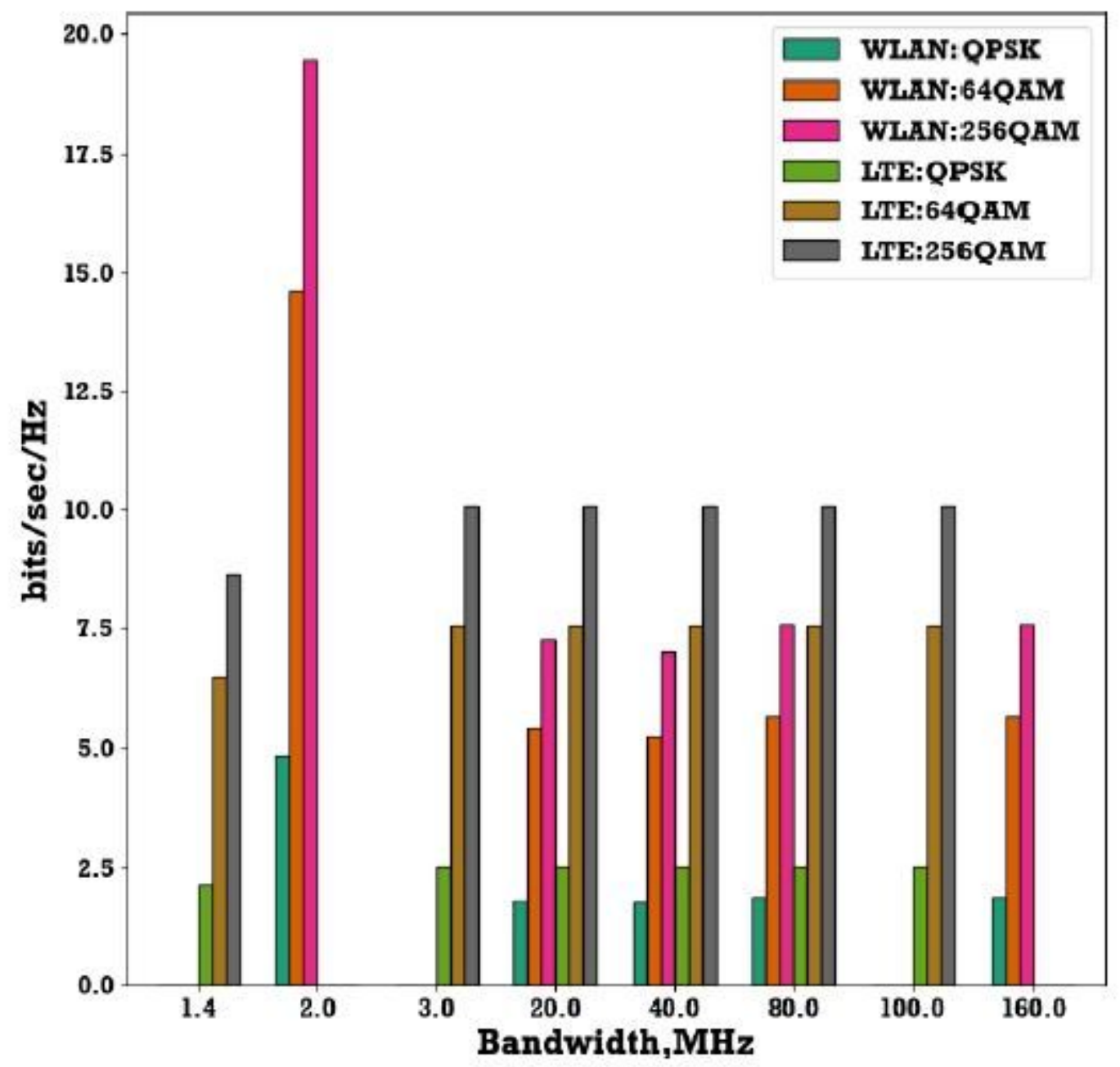

Figure 5

Spectral efficiency per DA in LTE-DAS and AP in WiFi-6 for different bandwidths. 